\title{
Cost effectiveness and affordability of trastuzumab in sub-Saharan Africa for early stage HER2-positive breast cancer
}

\author{
Noga Gershon ${ }^{*}{ }^{\mathbb{D}}$, Yakir Berchenko ${ }^{1}$, Peter S. Hall ${ }^{2}$ and Daniel A. Goldstein ${ }^{3,4}$
}

\begin{abstract}
Background: Breast cancer is the second most common cancer worldwide, the most common among women, and the most frequent cause of death among women in less developed regions. Trastuzumab is a humanized monoclonal antibody that downregulates the extracellular domain of the HER2 protein. Using trastuzumab to treat women with localized HER2-positive breast cancer has been shown to improve survival. The objective of this study is to explore the cost-effectiveness of adjuvant trastuzumab, from a societal perspective, in 11 African countries. In addition, we aimed to establish value-based prices for trastuzumab based on the gross domestic product per capita in each country.
\end{abstract}

Methods: We developed a Markov model in order to assess the costs and benefits associated with trastuzumab treatment over a lifetime horizon. A probabilistic sensitivity analysis was performed in order to estimate the impact of uncertainty of parameter-values on the results. Efficacy inputs were derived using clinical trial data from non-African countries.

Results: In the base case analysis, trastuzumab yielded a gain ranging from $0.92 \mathrm{LYS}$ in Nigeria to $1.07 \mathrm{LYs}$ in South Africa, and 0.9 QALYs in Nigeria to 1.02 QALYs in South Africa. The incremental cost ranged from 19,561 USD in Nigeria to 19,997 USD in Congo, and an incremental cost-effectiveness ratio ranging from 19,534 USD/QALY in South Africa to 21,697 USD/QALY in Nigeria. Using willingness to pay estimates based on World Health Organization recommendations, trastuzumab appear to not be cost-effective in all countries analyzed. Cost-effectiveness estimates were most sensitive to the discount rate, trastuzumab cost, and the hazard ratio.

Conclusions: Trastuzumab does not appear to be cost effective in the African countries analyzed. In order for trastuzumab to be cost-effective, the costs of treatment would require significant discounts.

Keywords: Cost-effectiveness, Trastuzumab, Sub-Saharan Africa

\section{Background}

Non-communicable diseases, are responsible for about $70 \%$ of deaths worldwide. It was predicted that by 2050 , 24 million people will be diagnosed with cancer annually. Among them, up to $70 \%$ will be from low-income and middle-income (LMICs) countries [1]. The increasing incidence in these countries is due to lifestyle changes, increased life expectancy, and the improvements in

\footnotetext{
*Correspondence: nogagers@post.bgu.ac.il

${ }^{1}$ Ben-Gurion University of the Negev, P.O.B. 653, Beer-Sheva 8410501, Israel

Full list of author information is available at the end of the article
}

treating infectious diseases [1]. Health care systems in many African countries are struggling to deal with the increasing demand caused by the increasing number of cancer patients. Furthermore, using the same care guidelines from high-income countries in a region with less resources and fewer personnel is inappropriate. The high mortality of cancer patients in Africa is multifactorialdue to poor infrastructure, lack of skilled health-care workers, advanced stage at diagnosis, reliance on traditional therapy, few treatment options, and poor compliance [2]. According to a report published by the Institute of Medicine (IOM), the burden of cancer is growing in many poor countries [3]. Breast cancer is the second 
most common cancer worldwide, and the most common among women. Moreover, breast cancer is the fifth most common cause of death overall, the most frequent cause of death among women in less developed regions, and the second cause of death in more developed regions [4].

Trastuzumab is a humanized monoclonal antibody that downregulates the extracellular domain of the HER2 protein. Trastuzumab significantly increases the cure rate in patients with $H E R 2$ positive localized breast cancer, and has therefore become a standard adjuvant treatment for early stage breast cancer in many countries [5]. In a survey conducted on breast cancer management in Africa, trastuzumab was available in 10 out of 19 facilities. However, only $5 \%$ of the patients were able to afford it [6]. Due to minimal availability of data, there is very scant evidence regarding actual treatment patterns in sub-Saharan Africa. Furthermore, it was found that many breast cancer patients in sub-Saharan Africa are usually treated with tamoxifen regardless of their receptor status [2].

The aim of this study was to explore the cost-effectiveness and affordability of adjuvant trastuzumab treatment for HER2-positive breast cancer in 11 countries in subSaharan Africa, from a societal perspective. The decision whether an intervention is good value for money or not is determined by comparing the incremental cost-effectiveness ratio result (ICER) in each country to a specific willingness to pay (WTP) threshold [7]. In LMICs, the threshold suggested by the World Health Organization (WHO) is related to the annual gross domestic product (GDP) per capita of each country. If the ICER of the intervention is less than $1 x$ GDP per capita, the intervention is considered as very cost-effective. If the ICER is between 1 and $3 \times$ GDP per capita, the intervention is considered cost-effective. Otherwise, it is considered not cost-effective [7]. In order to use WHO's suggested threshold, the ICER should be in terms of cost per DALY (disability-adjusted life year) [7], however according to a study that reviewed the cost-effectiveness literature, it was found that cost-per quality adjusted life year (QALY) is used to address diseases in wealthier countries such as cancer, whereas cost-per DALY tend to address more prevalent diseases in low income countries such as HIV. Furthermore, QALYs tend to be used for interventions that evaluate pharmaceuticals, while DALYs are used to evaluate interventions that are more focused on immunizations [8]. Additionally, the use of a figure close to the GDP per capita as a cost-effectiveness threshold is widespread in many countries. For example, the United States cost-effectiveness ratio, as for 2016 was 50,000 USD per QALY, while their GDP per capita was 57,588 USD. The United Kingdom cost-effectiveness threshold as for 2016, was set to be 20,000-30,000 GBP/ QALY ( 25,245-37,867 USD per QALY), and the GDP per capita was 40,412 USD [9]. The Netherlands costeffectiveness threshold was set to 40,000 EUR per QALY ( 45,498 USD), and the GDP per capita was 45,637 USD [10]. Australia's GDP per capita is 53,800 USD, however they do not have a specific threshold for funding a new medicine. However, it is more likely that a new drug that costs less than 50,000 USD per QALY will recommended for funding [11]. In Mexico, when deciding whether or not to include a certain technology in the public healthcare system, the GDP per capita is defined to be the costeffectiveness threshold [12]. This threshold is also being used in Chile [13] and Colombia [14] to define a technology as cost-effective. Following that, we decided to use the GDP per capita threshold to determine whether trastuzumab is cost-effective or not in sub-Saharan Africa. Furthermore, with DALY being typically an intermediate between LY and QALY, since in our paper the LY and QALY obtained are not far apart (and thus, replacing either by DALY will not change much), the extra pagespace and demand from the reader seem unwarranted. An additional objective of this paper was to estimate a value-based price (VBP) for each country based on each country's GDP per capita.

\section{Methods}

We developed a Markov model with monthly cycles and life time horizon using the Rstudio platform. The model was used to estimate the costs and health outcomes (LYs, QALYs) associated with two treatment strategies (chemotherapy with and without trastuzumab) for treating early stage HER2 positive breast cancer. The chemotherapy regimen used in this model is anthracycline based chemotherapy as depicted in the HERA trial $[15,16]$. However, there are multiple different approaches regarding timing and precise therapy such as the use of taxane based therapy, depending on the patient and stage of disease. However, as the precise treatment patterns in sub-Saharan Africa are unknown, it would only be speculation to suggest that one chemotherapy is used in preference of another. This limits the applicability of this model.

\section{Model structure}

The Markov model was developed using the model structure and data used in a recently published study concerning the cost-effectiveness of trastuzumab in South-America [17]. The structure of the model was quite similar to several previously published cost-effectiveness analyses concerning trastuzumab [18-21]. The HERA trial is considered by many to be the most pivotal trial due to the statistically significant results. There have however been considerations that a shorter duration of treatment may be a reasonable option. The FinnHER study evaluated the use of trastuzumab for only 9 weeks 
compared to no trastuzumab [22]. However this short duration was not compared to the longer duration and did not become accepted as a standard of care around the world. One exception to this was in New Zealand, where the government initially provided 9 weeks of therapy, but then decided to provide 12 months of therapy [23] following demonstration of lack of non-inferiority with the shorter course [24].

Other studies such as the PERSEPHONE trial [25] have assessed the efficacy of using 6 months of trastuzumab, however this has still not become the standard of care due to multiple statistical considerations. A recent metaanalysis suggested preferential clinical outcomes with 12 months of therapy.

The inputs of the model were based upon the HERA trial $[15,16,26]$ which was used to construct prior costeffectiveness analyses. Even though the HERA trial was conducted in HIC, we had no reason to believe that the efficacy and side effect profile are different among different ethnic groups. The model illustrated in Fig. 1, consists of five different states: "Remission" (R), "Loco-regional recurrence" (LR), "Distant recurrence" (DR) including metastasis, "Breast cancer death" (BCD), and "Death due to other causes" (D). Patients enter the model from the "Remission" state, they can move to "Loco-regional recurrence" (LR) and return to "Remission" after a successful treatment. They can move from the "Remission" (R) state to "Distant recurrence" (DR) when metastasis is developed. Patients in "Loco-regional recurrence" (LR) state can move to "Distant recurrence" (DR). Patients in all states can move to the "Death due to other causes" (D) state due to all-cause mortality. Only patients in "Distant recurrence" (DR) state can move to "Breast cancer death" (BCD). The influence of trastuzumab on the patients was modeled by changing the transition probabilities from $\mathrm{R}$ to DR and from LR to DR for the trastuzumab arm, using

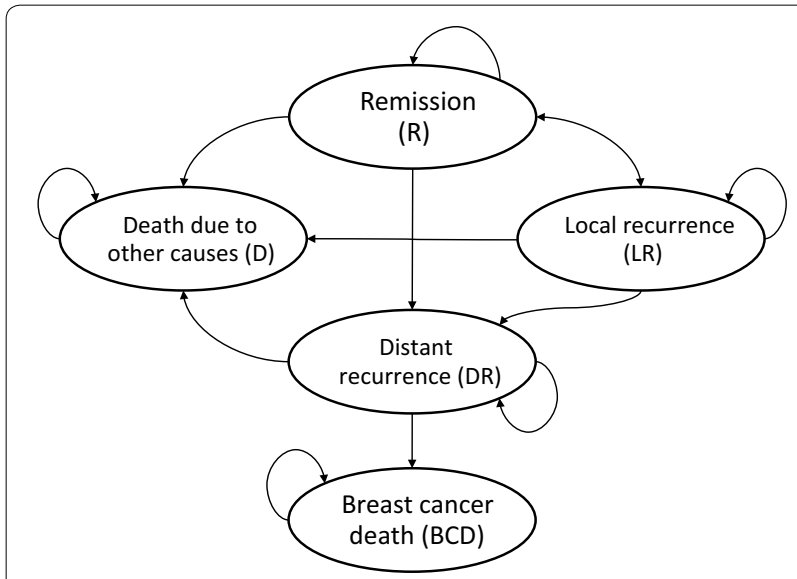

Fig. 1 Markov model structure the hazard ratio. The probability of moving from DR to BCD is identical for both arms. This is because using trastuzumab only delays or prevents a patient from moving to the DR state. Once a patient has arrived in the DR state, the probability of staying in this state, or moving to other states is identical regardless of the patient's arm. It was assumed that the effect of trastuzumab lasted 5 years and that there were no cancer recurrences after 20 years of follow-up [17]. Moreover, heart failure incidence that was reported in the trastuzumab trials was not incorporated in the model since it is reversible, and is not associated with increased mortality $[27,28]$.

The model outputs were costs, life years (LYs), QALYs and ICERs. Costs, LYs, and QALYs were discounted at a yearly rate of 3\% as recommended by the WHO [29].

\section{Patient population}

For each treatment strategy, a hypothetical cohort of 10,000 patients was simulated.

Patients who enter the model are 45 years corresponding with the median age of breast cancer patients in Africa [30]. Few studies were conducted concerning the clinicopathological and biological characteristics of breast cancer in sub-Saharan Africa [31]. Information on the incidence of HER2 positive, as presented in different studies, can be found in Table 1. Approximately $25 \%$ of breast cancers are HER 2 positive, and only those patients are eligible to receive trastuzumab. Therefore, the model was developed to evaluate the cost-effectiveness of trastuzumab only in HER2 positive patients. In this study, we assumed all patients have $H E R 2$ positive early stage breast cancer which was completely resected. The background mortality information of the patients was retrieved from the WHO Global Health Observatory data repository [32]. These values are different for patients from different countries (see Additional file 1: Table S1 and Additional file 2: Figure S1).

Table 1 HER2 positive incidence

\begin{tabular}{lll}
\hline Country & Incidence & Sources \\
\hline Congo & Not found & \\
Ethiopia & $23 \%$ & {$[31]$} \\
Guinea & Not found & \\
Kenya & $26 \%$ & {$[33]$} \\
Namibia & Not found & \\
Nigeria & $26 \%$ & {$[34]$} \\
Rwanda & $26.3 \%$ & {$[35]$} \\
Uganda & $22 \%$ & {$[36]$} \\
Zambia & Not found & \\
Zimbabwe & Not found & \\
South Africa & $22.50 \%$ & {$[37]$} \\
\hline
\end{tabular}




\section{Costs}

The total costs for the trastuzumab treatment were based on a first dose of $8 \mathrm{mg} / \mathrm{kg}$, followed by sixteen doses of $6 \mathrm{mg} / \mathrm{kg}$ for women that weigh $60 \mathrm{~kg}$, based on the average weight of women in the selected countries [38, 39], considering $10 \%$ drug wastage. The price of trastuzumab treatment was estimated from extensive negotiations made as has been indicated as a realistic discount based on prior negotiations [40]. Since chemotherapy was used in both arms, we decided to disregard its price as it will add up the same amount in both arms costs and it will eventually cancel each other out in the ICER calculation. The prices for the local and distant recurrence states (LR and DR) were estimated from the prices in Bolivia, as previously published [17], normalized by GDP per capita. We assumed that there is no cost for the "Remission" state in African countries (see Table 2).

GDP per capita values were retrieved from the World Bank database [41].

Table 2 Cost inputs

\begin{tabular}{llcc}
\hline Country/costs (USD) & $\begin{array}{l}\text { Trastuzumab } \\
\text { treatment }\end{array}$ & Local recurrence & $\begin{array}{l}\text { Distance } \\
\text { recurrence }\end{array}$ \\
\hline Congo & 20,000 & 974 & 1356 \\
Ethiopia & 20,000 & 1323 & 1841 \\
Guinea & 20,000 & 1136 & 1581 \\
Kenya & 20,000 & 2769 & 3853 \\
Namibia & 20,000 & 9719 & 13,524 \\
Nigeria & 20,000 & 5446 & 7578 \\
Rwanda & 20,000 & 1456 & 2027 \\
Uganda & 20,000 & 1424 & 1981 \\
Zambia & 20,000 & 2695 & 3751 \\
Zimbabwe & 20,000 & 2090 & 2909 \\
South Africa & 20,000 & 11,836 & 16,470
\end{tabular}

\section{Quality of life}

We incorporated quality of life data from previously published data and these are presented in Table 3 [17].

\section{Sensitivity analyses}

In order to assess the robustness of the model, a probabilistic sensitivity analysis was performed in order to assess the impact of uncertain variables on the results. Each variable was varied separately according to the probability distribution of each variable as described in Table 3.

\section{Results}

In the base case analysis, trastuzumab yielded a gain ranging from 0.92 LYs in Nigeria to 1.07 LYs in South Africa, and 0.9 QALYs in Nigeria to 1.02 QALYs in South Africa. The ICER ranged from 19,534 USD/QALY in South Africa to 21,697 USD/QALY in Nigeria. Results are presented in Table 4 and in Additional file 3: Figure S2.

Uncertain values of the model were varied in a oneway probabilistic sensitivity analysis. Results for all countries are presented in Fig. 2. The diagram presents ICER results from the 0.25 percentile to the 0.75 percentile. The probabilistic sensitivity analysis results were consistent through all 11 countries. The most sensitive variables were the discount rate, trastuzumab cost, and the hazard ratio. Furthermore, as can be seen in the figure, trastuzumab is not considered costeffective even with the low ICER values in the sensitivity analysis. Even though the prices used through most countries are identical as well as the drug efficacy, the ICER of each country is different due to the variation in background mortality of each country.

The individual estimates of valued based prices for trastuzumab are presented in Figs. 3, 4 and in Table 5. Since it was concluded that trastuzumab is not

Table 3 Model parameters used in the base case analysis and distributions used for the sensitivity analysis

\begin{tabular}{|c|c|c|c|}
\hline Description & Value & Distribution & Sources \\
\hline \multicolumn{4}{|l|}{ Utilities } \\
\hline Remission (R) & 0.94 & Beta $(89,6)$ & {$[42,43]$} \\
\hline Local recurrence (LR) & 0.82 & Beta $(77,23)$ & {$[16]$} \\
\hline Distant recurrence (DR) & 0.58 & Beta $(171,79)$ & {$[16]$} \\
\hline \multicolumn{4}{|l|}{ Transition probabilities } \\
\hline$R>L R$ & 0.029 & Beta $(27,983)$ & {$[26]$} \\
\hline$R>D R$ & 0.087 & Beta $(102,1061)$ & {$[15,16]$} \\
\hline$L R>R$ & 0.1 & Beta $(111,899)$ & {$[16]$} \\
\hline$L R>D R$ & 0.261 & Beta $(119,931)$ & {$[16]$} \\
\hline $\mathrm{DR}>\mathrm{BCD}$ & 0.325 & Beta $(15,20)$ & {$[16]$} \\
\hline$R, D R, L R>D$ & All-cause mortality & Age-specific mortality & {$[32]$} \\
\hline Hazard ratio years 1-5 & 0.59 & Log-Normal $(-0.527,0.089)$ & {$[16,44]$} \\
\hline
\end{tabular}


Table 4 Mean base case results

\begin{tabular}{|c|c|c|c|c|c|c|}
\hline Country & Results & LYs & QALYs & Costs (USD) & ICER (\$/QALY) & ICER (\$/LY) \\
\hline \multirow[t]{3}{*}{ Congo } & No Tzb arm & 8.88 & 7.72 & 2588 & 20,520 & 19,701 \\
\hline & Tzb arm & 9.89 & 8.69 & 22,585 & & \\
\hline & Diffrence & 1.01 & 0.97 & 19,997 & & \\
\hline \multirow[t]{3}{*}{ Ethiopia } & No Tzb arm & 8.87 & 7.71 & 3541 & 19,990 & 19,384 \\
\hline & Tzb arm & 9.90 & 8.70 & 23,457 & & \\
\hline & Diffrence & 1.03 & 1.00 & 19,916 & & \\
\hline \multirow[t]{3}{*}{ Guinea } & No Tzb arm & 8.65 & 7.52 & 2955 & 20,692 & 20,025 \\
\hline & Tzb arm & 9.65 & 8.48 & 22,898 & & \\
\hline & Diffrence & 1.00 & 0.96 & 19,943 & & \\
\hline \multirow[t]{3}{*}{ Kenya } & No Tzb arm & 8.96 & 7.79 & 7467 & 19,601 & 18,709 \\
\hline & Tzb arm & 10.03 & 8.80 & 27,448 & & \\
\hline & Diffrence & 1.07 & 1.02 & 19,982 & & \\
\hline \multirow[t]{3}{*}{ Namibia } & No Tzb arm & 8.69 & 7.54 & 25,549 & 19,818 & 19,125 \\
\hline & Tzb arm & 9.72 & 8.53 & 45,173 & & \\
\hline & Diffrence & 1.03 & 0.99 & 19,624 & & \\
\hline \multirow[t]{3}{*}{ Nigeria } & No Tzb arm & 8.51 & 7.39 & 14,066 & 21,697 & 21,321 \\
\hline & Tzb arm & 9.43 & 8.29 & 33,628 & & \\
\hline & Diffrence & 0.92 & 0.90 & 19,561 & & \\
\hline \multirow[t]{3}{*}{ Rwanda } & No Tzb arm & 8.98 & 7.80 & 3919 & 19,751 & 19,004 \\
\hline & Tzb arm & 10.03 & 8.81 & 23,894 & & \\
\hline & Diffrence & 1.05 & 1.01 & 19,975 & & \\
\hline \multirow[t]{3}{*}{ Uganda } & No Tzb arm & 8.79 & 7.63 & 3793 & 20,477 & 19,806 \\
\hline & Tzb arm & 9.80 & 8.61 & 23,738 & & \\
\hline & Diffrence & 1.01 & 0.97 & 19,945 & & \\
\hline \multirow[t]{3}{*}{ Zambia } & No Tzb arm & 8.75 & 7.60 & 7116 & 20,330 & 19,473 \\
\hline & Tzb arm & 9.77 & 8.58 & 27,074 & & \\
\hline & Diffrence & 1.02 & 0.98 & 19,958 & & \\
\hline \multirow[t]{3}{*}{ Zimbabwe } & No Tzb arm & 8.57 & 7.44 & 5458 & 20,537 & 20,086 \\
\hline & Tzb arm & 9.56 & 8.41 & 25,303 & & \\
\hline & Diffrence & 0.99 & 0.97 & 19,845 & & \\
\hline \multirow[t]{3}{*}{ South Africa } & No Tzb arm & 8.76 & 7.61 & 31,160 & 19,534 & 18,719 \\
\hline & Tzb arm & 9.83 & 8.63 & 51,119 & & \\
\hline & Diffrence & 1.07 & 1.02 & 19,960 & & \\
\hline
\end{tabular}

The standard error for LYs, QALYs, trastuzumab cost and no trastuzumab cost ranged from $0.052 \mathrm{LYs}$ to $0.056 \mathrm{LY}, 0.049$ QALYs to 0.053 QALYs, 27 USD to 328 USD, and 27 USD to 324 USD respectively

cost-effective in the examined countries, we calculated the VBP in such a way that would make the treatment considered as cost-effective in each country, when the WTP threshold is one GDP per capita. In order for the treatment to be considered as cost-effective in African countries, significant price reductions would be required.

\section{Discussion}

In this paper, the cost-effectiveness of trastuzumab for treating breast cancer was examined. Trastuzumab was compared to conventional chemotherapy treatment. In this analysis, trastuzumab treatment yields a gain ranging from 0.92 LYs in Nigeria to 1.07 LYs in South Africa, and 0.9 QALYs in Nigeria to 1.02 QALYs in South Africa, with an incremental cost ranging from 19,561 USD in Nigeria to 19,997 USD in Congo, and an incremental cost-effectiveness ratio ranging from 19,534 USD/QALY in South Africa to 21,697 USD/QALY in Nigeria per gained QALY.

The ICER results were comparable to previously published results [19, 43-45]. Prior analyses in the UK, Australia, United States and Italy yielded similar results to those in our analysis. Other papers presented higher ICERs, which may be due to calculated costs and survival rates in Africa being significantly lower [18, 46, 47]. 


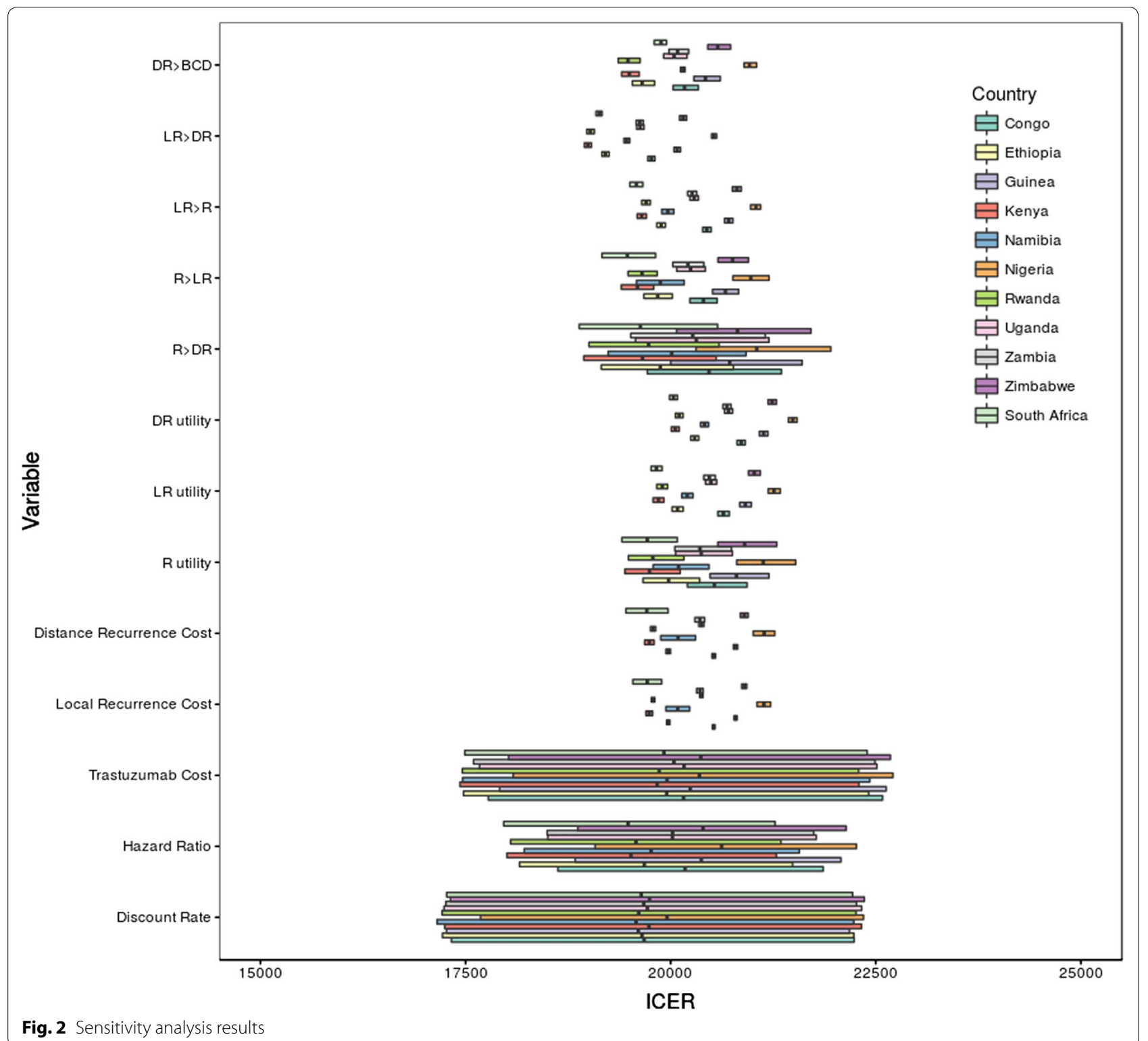

Although the ICER results are quite similar to other studies, their meaning is different when examined in Africa. While trastuzumab can be considered as costeffective in HICs [5, 21, 42-44, 48], this is not the case in LMICs. ICER results in HICs were close or below the suggested threshold by WHO, one GDP per capita, as can be seen in Table 6, while the calculated ICERs in Africa were significantly higher than one GDP per capita for each examined country.

This study has several limitations. Since no clinical trials were performed in Africa, there was a lack of information regarding the efficacy of the drug in the population in this area. Therefore, for this analysis it was assumed that the findings from the performed clinical trials are relevant in Africa as well. Additionally, although the median age of patients in the HERA trial was 49 , we used a different age (45) in our model under the assumption that the reported hazard ratio and the transition probabilities depend on disease progression rather than the age. Furthermore, as indicated by previous literature [30], 45 years old is more representative of the general population of patients in sub-Saharan Africa. Another limitation concerns the omission of heart failure from the model. Although heart failure is reversible and is not associated with increased mortality it may have a mild effect on quality of life estimates. However, since 

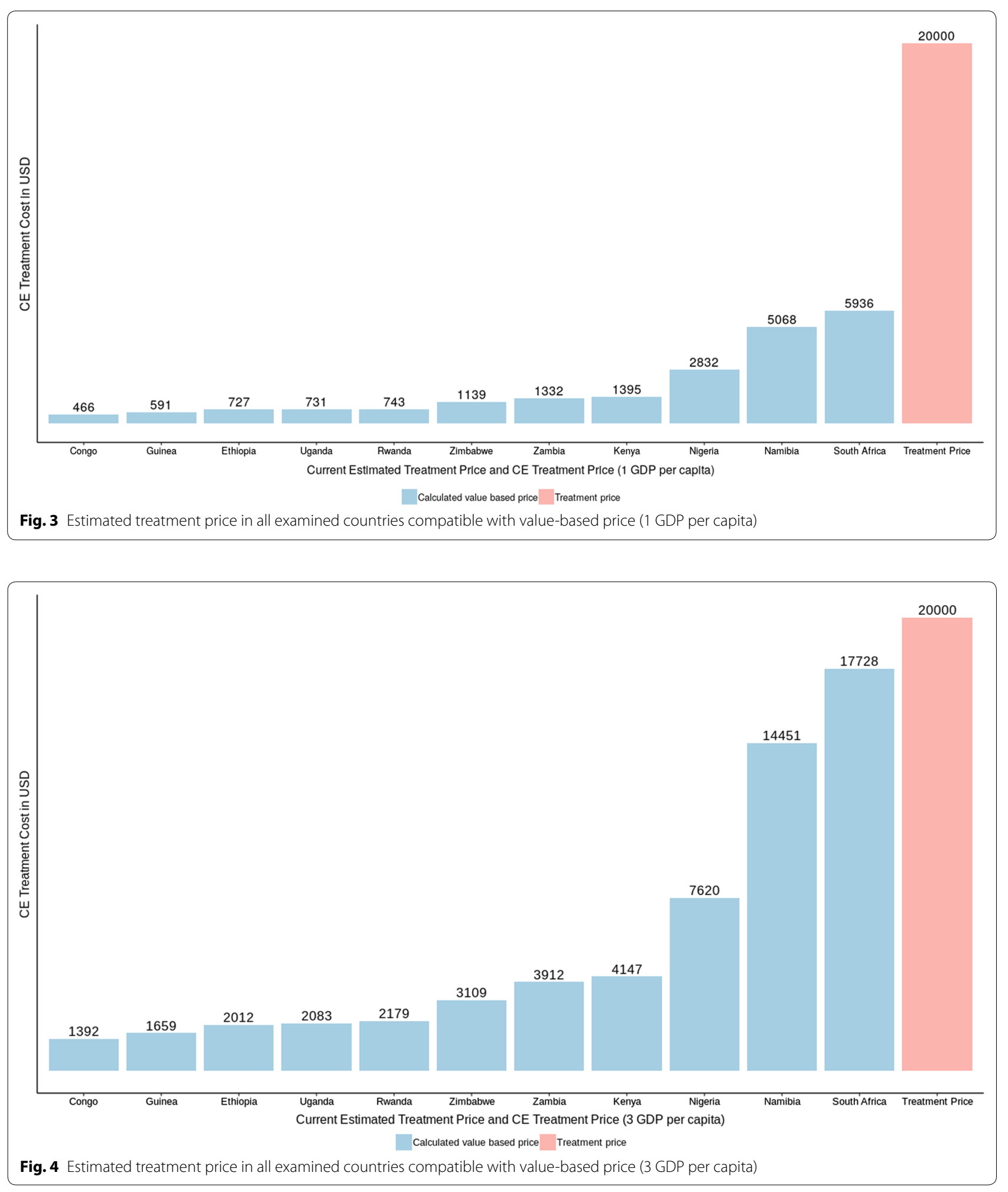

the incidence is very low $[27,28]$, we excluded it as it would have only a very minor impact on the results of the model. Moreover, given that the gap between the current results and the cost-effectiveness threshold is very large, it can be assumed that the inclusion of heart failure will not change the results significantly. Moreover, as stated before, the transition probabilities were based on the HERA trial, which was conducted in HICs. These 
Table 5 Value based price for each country

\begin{tabular}{lcc}
\hline Country & $\begin{array}{l}\text { Value based price (1 GDP } \\
\text { per capita) }\end{array}$ & $\begin{array}{l}\text { Value based price } \\
\text { (3 GDP per capita) }\end{array}$ \\
\hline Congo & 466 & 1392 \\
Ethiopia & 727 & 2012 \\
Guinea & 591 & 1659 \\
Kenya & 1395 & 4147 \\
Namibia & 5068 & 14,451 \\
Nigeria & 2832 & 7620 \\
Rwanda & 743 & 2179 \\
Uganda & 731 & 2083 \\
Zambia & 1332 & 3912 \\
Zimbabwe & 1139 & 3109 \\
South Africa & 5936 & 17,728
\end{tabular}

Table 6 ICER results and their corresponding GDP per capita

\begin{tabular}{lll}
\hline Country & ICER & $\begin{array}{l}\text { GDP } \\
\text { per capita } \\
\text { (USD) }\end{array}$ \\
\hline Switzerland & 40,505 EUR (45,950 USD) per LYG & 57,579 \\
United Kingdom & 25,803 GBP (33,073 USD) per QALY & 44,252 \\
Sweden & 41,500 USD per QALY & 46,256 \\
Norway & 35,974 EUR (40,810 USD) per LYG & 85,170 \\
United States & 26,417 USD per QALY & 48,061 \\
United States & 39,892 USD per QALY & 55,443 \\
\hline
\end{tabular}

probabilities were used due to lack of trials performed in sub-Saharan Africa. Therefore, it can be assumed that in reality these probabilities would be a bit different due to differences between health care systems in HICs and sub-Saharan Africa. Furthermore, not all the countries in Africa provide trastuzumab due to its high price. There is a significant lack of price transparency globally. Hence, the prices for all examined countries were merely estimated. Lastly, since we concluded trastuzumab is not cost-effective in the current setting (12 months treatment), further research concerning a recently suggested treatment duration (6/9 months treatment/9 weeks) [24, 49] needs to be further investigated and maybe adopted in sub-Saharan Africa.

Africa is facing a major public health challenge from noncommunicable diseases. Even though infectious diseases are still a major concern in Africa, the overall disease burden proportion in Africa associated with cancer is rising. It was predicted that by 2030 , this region will experience an increase of more than $85 \%$ cancer burden [50]. One way to improve the current state in Africa is to make cancer drugs more accessible and affordable. Major improvements in the health system and cancer awareness are also crucial.

\section{Conclusions}

In this work we calculate the expected ICER gained by using trastuzumab in sub-Sahara Africa, and compare it to the threshold recommended by the WHO. Although the ICER results are quite similar to other studies, their meaning is different when examined in sub-Sahara Africa. While a trastuzumab can be considered as costeffective in HICs, this is not the case in LMICs. ICER results in HICs were close or below the suggested threshold by WHO, one GDP per capita, while the calculated ICERs in Africa were significantly higher than one GDP per capita for each examined country.

Despite several limitations of our study, it seems that a significant reduction in trastuzumab's price (compared to its price in HICs) would be required in order for it to be cost-effective in sub-Sahara Africa.

\section{Additional files}

$$
\begin{aligned}
& \text { Additional file 1: Table S1. Probability of dying between ages } x \text { and } x+5 \\
& \text { for each country. } \\
& \text { Additional file 2: Figure S1. Probability of dying between ages } x \text { and } \\
& x+5 \text { for each country. } \\
& \text { Additional file 3: Figure S2. ICER (incremental cost-effectiveness ratio) } \\
& \text { results for each country. }
\end{aligned}
$$

\section{Abbreviations}

QALY: quality-adjusted life year; LY: life-year; LMICs: low-income and middleincome; ICER: incremental cost-effectiveness ratio result; Tzb: trastuzumab; WTP: willingness to pay; WHO: World Health Organization; GDP: gross domestic product; DALY: disability-adjusted life year; VBP: value-based price.

\section{Authors' contributions}

NG, YB, PSH, and DAG designed the study, NG assembled the data and programmed the model. NG, YB, and DAG performed the statistical analyses, interpreted the results, and provided a draft of the manuscript. DAG and

PSH critically reviewed the manuscript. Final approvement was made by all authors. All authors agreed to be accountable for all aspects of the work. All authors read and approved the final manuscript.

\section{Author details}

${ }^{1}$ Ben-Gurion University of the Negev, P.O.B. 653, Beer-Sheva 8410501, Israel. 2 Edinburgh Cancer Research Centre, Western General Hospital, Edinburgh, UK. ${ }^{3}$ Davidoff Cancer Center, Rabin Medical Center, Petach Tikvah, Israel. ${ }^{4}$ Department of Health Policy and Management, University of North Carolina, Chapel Hill, USA.

\section{Acknowledgements}

The authors would like to thank Lawrence Shulman for providing the pricing information as well as further helpful discussions.

\section{Competing interests}

The authors declare that they have no competing interests.

\section{Availability of data and dataset}

All data are detailed in the paper and can also be found in the referenced literature. $\mathrm{R}$ code available upon request.

\section{Consent for publication}

All authors consent to the publication of this manuscript; additional consent is not applicable. 
Ethics approval and consent to participate

Not applicable.

\section{Funding}

No funding.

\section{Publisher's Note}

Springer Nature remains neutral with regard to jurisdictional claims in published maps and institutional affiliations.

Received: 16 July 2018 Accepted: 19 February 2019

Published online: 28 February 2019

\section{References}

1. Parkin D, Bray F, Devesa S. Cancer burden in the year 2000. The global picture. Eur J Cancer. 2001;37:4-66. https://doi.org/10.1016/S0959 -8049(01)00267-2

2. Kingham TP. Series cancer control in Africa 3 treatment of cancer in subSaharan Africa. Lancet Oncol. 2013;14:e158-67. https://doi.org/10.1016/ S1470-2045(12)70472-2.

3. Institute of Medicine. Cancer control opportunities in low- and middleincome countries. vol 57. 2007. https://www.ncbi.nlm.nih.gov/books/ NBK54030/pdf/Bookshelf_NBK54030.pdf. Accessed Sept 142017.

4. Ferlay J, Soerjomataram I, Dikshit R, et al. Cancer incidence and mortality worldwide: sources, methods and major patterns in GLOBOCAN 2012. Int J Cancer. 2015;136(5):E359-86. https://doi.org/10.1002/ijc.29210.

5. Dedes KJ, Szucs TD, Imesch P, Fedier A, Fehr MK, Fink D. Cost-effectiveness of trastuzumab in the adjuvant treatment of early breast cancer: a modelbased analysis of the HERA and FinHer trial. Ann Oncol. 2007:18:1493-9. https://doi.org/10.1093/annonc/mdm185.

6. Vanderpuye VDNK, Olopade OI, Huo D. Pilot survey of breast cancer management in Sub-Saharan Africa. J Glob Oncol. 2017;3(3):194-200. https:// doi.org/10.1200/JGO.2016.004945

7. Bertram MY, Lauer JA, De Joncheere K, et al. Cost-effectiveness thresholds: pros and cons. Bull World Health Organ. 2016;94(12):925-30. https:// doi.org/10.2471/BLT.15.164418.

8. Neumann PJ, Anderson JE, Panzer AD, et al. Comparing the cost-perQALYs gained and cost-per-DALYs averted literatures. Gates Open Res. 2018;2(52):5. https://doi.org/10.12688/gatesopenres.12786.1.

9. Woods B, Revill P, Sculpher M, Claxton K. Country-level cost-effectiveness thresholds: initial estimates and the need for further research. Value Heal. 2016;19:929-35. https://doi.org/10.1016/j.jval.2016.02.017.

10. Griffiths $E$, Vadlamudi N. Cadth's $\$ 50,000$ cost-effectiveness threshold: fact or fiction? Value Heal. 2016;19(7):A488-9. https://doi.org/10.1016/j. jval.2016.09.821.

11. Taylor C, Jan S. Economic evaluation of medicines. Aust Prescr. 2017;40(2):76-8. https://doi.org/10.18773/austprescr.2017.014.

12. Consejo de Salubridad General. Guía de Evaluación de Insumos para la Salud. 2015:67. http://www.csg.gob.mx/descargas/pdf/priorizacion/ cuadro-basico/guias/insumos_salud/GEl_2017_Diciembre.pdf. Accessed 20 Dec 2018.

13. Nacional E, Pública DS, Finlay CJ, Salud SY, Para R, Acción LA. Revista Cubana de Salud Pública. Rev Cuba Salud Pública. 2000;26(1):91-100. http://scielo.sld.cu/scielo.php?script=sci_arttext\&pid=S0864-34662 004000100005. Accessed 20 Dec 2018

14. Moreno Viscaya M, Mejía Mejía A, Castro Jaramillo HE. Manual Para La Elaboración de Evaluaciones Económicas En Salud. Colombia: Instituto de Evaluación Tecnológica en Salud I; 2014. https://doi.org/10.13140 /2.1.4034.3049.

15. Smith I, Procter M, Gelber RD, et al. 2-year follow-up of trastuzumab after adjuvant chemotherapy in HER2-positive breast cancer: a randomised controlled trial. Lancet. 2007;369(9555):29-36. https://doi.org/10.1016/ S0140-6736(07)60028-2.

16. Piccart-Gebhart MJ, Procter M, Leyland-Jones B, et al. Trastuzumab after adjuvant chemotherapy in HER2-positive breast cancer. N Engl J Med. 2005:353:1659-72. https://doi.org/10.1056/NEJMoa052306.

17. Pichon-Riviere A, Garay OU, Augustovski F, et al. Implications of global pricing policies on access to innovative drugs: the case of trastuzumab in seven latin American countries. Int J Technol Assess Health Care. 2015;31(1-2):2-11. https://doi.org/10.1017/S0266462315000094.

18. Aboutorabi A, Hadian M, Ghaderi H, Salehi M, Ghiasipour M. Costeffectiveness analysis of trastuzumab in the adjuvant treatment for early breast cancer. Glob J Health Sci. 2015. https://doi.org/10.5539/gjhs.v7n1p 98.

19. Millar JA, Millward MJ. Cost effectiveness of trastuzumab in the adjuvant treatment of early a lifetime model. Glob J Health Sci. 2007;25(5):429-42.

20. Seferina SC, Ramaekers BLT, De Boer M, Wouter M. Cost and costeffectiveness of adjuvant trastuzumab in the real world setting : a study of the Southeast Netherlands Breast Cancer Consortium. Oncotarget. 2017:8:79223.

21. Kurian AW, Thompson RN, Gaw AF, Arai S, Ortiz R, Garber AM. A costeffectiveness analysis of adjuvant trastuzumab regimens in early HER2/ neu-positive breast cancer. J Clin Oncol. 2007;25(6):634-41. https://doi. org/10.1200/JCO.2006.06.3081.

22. Joensuu H, Bono P, Kataja V, et al. Fluorouracil, epirubicin, and cyclophosphamide with either docetaxel or vinorelbine, with or without trastuzumab, as adjuvant treatments of breast cancer: final results of the FinHer trial. J Clin Oncol. 2009;27(34):5685-92. https://doi.org/10.1200/ JCO.2008.21.4577.

23. Herald N. Year-long Herceptin treatment proven to be most effective for breast cancer. https://www.nzherald.co.nz/nz/news/article.cfm?c_ $i d=1 \&$ objectid=11956261. Accessed 5 Feb 2019.

24. Joensuu $H$, Fraser J, Wildiers $H$, et al. Effect of adjuvant trastuzumab for a duration of 9 weeks vs 1 year with concomitant chemotherapy for early human epidermal growth factor receptor 2-positive breast cancer: The SOLD Randomized Clinical Trial. JAMA Oncol. 2018;4(9):1199-206. https:// doi.org/10.1001/jamaoncol.2018.1380.

25. Earl HM, Hiller L, Vallier A-L, et al. PERSEPHONE: 6 versus 12 months ( $m$ ) of adjuvant trastuzumab in patients (pts) with HER2 positive $(+)$ early breast cancer (EBC): Randomised phase 3 non-inferiority trial with definitive 4-year (yr) disease-free survival (DFS) results. J Clin Oncol. 2018;36(15 suppl):506. https://doi.org/10.1200/jco.2018.36.15_suppl.506.

26. Gianni L, Dafni U, Gelber RD, et al. Treatment with trastuzumab for 1 year after adjuvant chemotherapy in patients with HER2-positive early breast cancer: a 4-year follow-up of a randomised controlled trial. Lancet Oncol. 2011;12(3):236-44. https://doi.org/10.1016/S1470-2045(11)70033-X

27. Suter TM, Procter M, Van Veldhuisen DJ, et al. Trastuzumab-associated cardiac adverse effects in the herceptin adjuvant trial. J Clin Oncol. 2007;25:3859-65. https://doi.org/10.1200/JCO.2006.09.1611.

28. Tan-Chiu E, Yothers G, Romond E, et al. Assessment of cardiac dysfunction in a randomized trial comparing doxorubicin and cyclophosphamide followed by paclitaxel, with or without trastuzumab as adjuvant therapy in node-positive, human epidermal growth factor receptor 2-overexpressing breast cancer: NSABP B-31. J Clin Oncol. 2005;23(31):7811-9. https:// doi.org/10.1200/JCO.2005.02.4091.

29. WHO-CHOICE. Making choices in health: WHO guide to cost-effectiveness analysis. Glob Program Evid Health Policy. 2003. https://doi. org/10.1590/s1135-57272004000300012.

30. Vanderpuye V, Grover S, Hammad N, et al. An update on the management of breast cancer in Africa. Infect Agent Cancer. 2017;12(1):13. https ://doi.org/10.1186/s13027-017-0124-y.

31. Hadgu E, Seifu D, Tigneh W, et al. Breast cancer in Ethiopia: evidence for geographic difference in the distribution of molecular subtypes in Africa. BMC Womens Health. 2018;18(1):40. https://doi.org/10.1186/s1290 5-018-0531-2

32. $\mathrm{GHO} \mid$ By indicator $\mid \mathrm{nq} x$ - probability of dying between ages $x$ and $x+n$ (Mortality and global health estimates). WHO. http://apps.who.int/gho/ data/node.imr.LIFE_0000000030?lang=en. Accessed 9 Jan 2019.

33. Sayed S, Moloo Z, Wasike R, et al. Is breast cancer from Sub Saharan Africa truly receptor poor? Prevalence of ER/PR/HER2 in breast cancer from Kenya. Breast. 2014;23(5):591-6. https://doi.org/10.1016/j.breas t.2014.06.006.

34. Daramola AO, Banjo AA, Bennett A, Abdulkareem F, Shaaban AM. Breast cancer reporting in Lagos, Nigeria: implications for training and education in Africa. J Glob Oncol. 2016;2(6):397-402. https://doi.org/10.1200/ JGO.2015.003079.

35. O'Neil DS, Keating NL, Dusengimana JMV, et al. Quality of breast cancer treatment at a rural cancer center in Rwanda. J Glob Oncol. 2018;4:1-11. https://doi.org/10.1200/JGO.2016.008672. 
36. Kurokawa T, Nonami T, Kuroe K, et al. Nucleotide metabolism in remnant rat liver after major hepatic resection. Nippon Geka Gakkai zasshi. 2014;91(8):994-1000. https://doi.org/10.11604/pamj.2014.17.249.330.

37. Myburgh EJ, Langenhoven L, Grant KA, van der Merwe L, Kotze MJ. Clinical overestimation of her2 positivity in early estrogen and progesterone receptor-positive breast cancer and the value of molecular subtyping using blueprint. J Glob Oncol. 2017;3(4):314-22. https://doi.org/10.1200/ JGO.2016.006072

38. World Health Organization. GHO | By category | Mean body mass index trends, age-standardized $\left(\mathrm{kg} / \mathrm{m}^{2}\right)$ —estimates by country. Glob Heal Obs. http://apps.who.int/gho/data/view.main.CTRY12461. Accessed 21 Mar 2018.

39. World Data. info. Average Male Height | Find the average height of men and women. https://www.worlddata.info/average-bodyheight.php. Accessed 21 Mar 2018.

40. MD LS. Personal Communication. 2018.

41. Worldbank. GDP per capita (current US\$) | Data. https://data.worldbank. org/indicator/NY.GDP.PCAP.CD. Published 2015. Accessed 22 Nov 2017.

42. Norum J, Olsen JA, Wist EA, Lønning PE. Trastuzumab in adjuvant breast cancer therapy. A model based cost-effectiveness analysis. Acta Oncol. 2007;46(2):153-64. https://doi.org/10.1080/02841860601096841.

43. Garrison LP, Lubeck D, Lalla D, Paton V, Dueck A, Perez EA. Cost-effectiveness analysis of trastuzumab in the adjuvant setting for treatment of HER2-positive breast cancer. Cancer. 2007;110(3):489-98. https://doi. org/10.1002/cncr.22806

44. Hall PS, Hulme C, Mccabe C, Oluboyede Y, Round J, Cameron DA. Updated cost-effectiveness analysis of trastuzumab for early breast cancer toxicity and pattern of recurrence. PharmacoEconomics. 2011;29(5):415-32.

45. Liberato NL, Marchetti M, Barosi G. Cost effectiveness of adjuvant trastuzumab in human epidermal growth factor receptor 2-positive breast cancer. J Clin Oncol. 2007;25:625-33. https://doi.org/10.1200/ JCO.2006.06.4220

46. Lang HC, Chen HW, Chiou TJ, Chan ALF. The real-world cost-effectiveness of adjuvant trastuzumab in HER-2/neu-positive early breast cancer in Taiwan. J Med Econ. 2016;19(10):923-7. https://doi.org/10.1080/13696 998.2016.1185013.

47. Buendía JA, Vallejos C, Pichón-Rivière A. An economic evaluation of trastuzumab as adjuvant treatment of early HER2-positive breast cancer patients in Colombia. Biomédica. 2013;333333:411-7411. https://doi. org/10.7705/biomedica.v33i3.832.

48. Lidgren M, Jö Nsson B, Rehnberg C, Willking N, Bergh J. Cost-effectiveness of HER2 testing and 1-year adjuvant trastuzumab therapy for early breast cancer. Ann Oncol. 2008;19:487-95. https://doi.org/10.1093/annonc/ mdm488.

49. Ansaripour A, Uyl-de Groot CA, Redekop WK. Adjuvant trastuzumab therapy for early HER2-positive breast cancer in Iran: a cost-effectiveness and scenario analysis for an optimal treatment strategy. PharmacoEconomics. 2017. https://doi.org/10.1007/s40273-017-0557-6.

50. Morhason-Bello IO, Odedina F, RebbeckTR, et al. Challenges and opportunities in cancer control in Africa: a perspective from the African Organisation for Research and Training in Cancer. Lancet Oncol. 2013;14(4):e142-51. https://doi.org/10.1016/S1470-2045(12)70482-5.
Ready to submit your research? Choose BMC and benefit from:

- fast, convenient online submission

- thorough peer review by experienced researchers in your field

- rapid publication on acceptance

- support for research data, including large and complex data types

- gold Open Access which fosters wider collaboration and increased citations

- maximum visibility for your research: over 100M website views per year

At BMC, research is always in progress.

Learn more biomedcentral.com/submissions 